\title{
Status of Beijing Olympic Games Brands in Establishment of a
}

\section{Sports Power}

\author{
Houzhong Jin, Hongquan Li \& Guoying Yuan \\ Sports Economics and Management School, Central University of Finance and Economics \\ Beijing 100081, China \\ E-mail: jinhouzhong@126.com
}

Received: October 25, $2010 \quad$ Accepted: March 21, $2011 \quad$ doi:10.5539/ass.v7n6p25

Foundation Item: Planned Project of Philosophical and Social Sciences in Beijing (09BaZh126)

\begin{abstract}
From the dimensionality of the Beijing Olympic Games national brand, city brand, enterprise brand and national citizen brand, this article expounded the status of Beijing Olympic Games brands in establishment of a sports power. According to the authors, in the process of further pushing forward China from a major sports country to a sports power, we have to provide further development and protection to Beijing Olympic Games brands.
\end{abstract}

Keywords: Beijing Olympic Games, Brand, Sports power

The evaluation index system of sports power is centered by the overall indexes of sports power, an overall index system including the three indexes of competitive sports, mass sports and sports industry (Qiu Xue, 2010). In this system, the brand index is contained in the three indexes. Beijing Olympic Games brand is a heritage (Jin Houzhong, 2010) index which is "more enduring and more precious", so we have to provide further development and protection to this brand in pushing forward China from a major sports country to a sports power. From the dimensionality of the Beijing Olympic Games national brand, city brand, enterprise brand and national citizen brand, this article expounded the status of Beijing Olympic Games brands in establishment of a sports power. Beijing Olympic Games brand has not changed the history of Olympic Games, but is also pushing forward China to step into a historical progress of sports power.

\section{The status of national brand in establishment of a sports power}

The national brand is a concentrative reflection of management level of national image and national image refers to the overall evaluation of the international society on the relative stability of a country. It is constituted by multiple elements, such as the geographical environment of a country, its inside and outside policies, its development situation, its cultural features and its national styles and features, etc, and is affected by the hard power and soft power of a country. The hard power of a country can measure its specific resources and power, including pollution, territory, natural resources, economic strength, military strength, social power and authority and influences in the international affairs. In the process of establishing a sports power, US has held eight Olympic Games and has made use of the Olympic Games to promote its national brand and US culture to the greatest extent and enable US to become a worldwide recognized sports power. The Beijing Olympic Games in 2008 successfully promoted its national brand and Chinese culture with its highest state, established Chinese image and status in the international word and exhibited the national brand. The national brand of harmony, self-confidence and tolerance has obtained the extensive recognition of the international world.

In the brand of harmony, the ideals of harmonious and perfect "scientific Olympics, humanistic Olympics and green Olympics" and "one world, one dream" perfectly supplements the Olympic culture of "higher, faster and stronger", enables the Chinese civilization of long standing to creatively realize integration with Olympic Games culture and implants new connotation for "peace, friendliness and progress". In the brand of self-confidence, before and after the Beijing Olympic Games was held, in face of all kinds of doubts and censures from the western countries, Chinese people from the national leaders to the common public didn't blame or complain at all. On the contrary, they came to encounter all these issues with an understanding and tolerant attitude, 
embraced all with a broad mind, changed misunderstandings into confidence with indisputable facts and let censure become high commendations, which fully indicated the self-confidence of the Chinese nation. In the brand of tolerance, Chinese people regarded those "collisions of different thinking modes" as a process of learning. "In order to maintain and exhibit a perfect national image, Chinese people listened to and accepted different voices with a tolerant and calm mind, sincerely pushed forward cross-cultural communication and exchange and regarded it as the motive to sustainable development and progress" (Dong Xiaoying \& Peng Siqing, 2008). In the process of further pushing forward China from a major sports country to a sports power, we should stand on a historical height, re-survey and self-check with introspection the "national characters", and further developed and protected the national brand of harmony, self-confidence and tolerance to enable the national brand to become the spiritual backbone of establishing a sports power.

\section{The status of city brand in establishment of a sports power}

In the 70s of the Twentieth Century, politics, entrepreneurs and other stakeholders saw sports as a tool to enhance image and appeal of a city, especially image and appeal of a region. They thought that sports was one of a few of means to mould the image of a city (Rio, Eric Alexander, 2006). In the current world of globalization, a city organization holds the large scale sports events of Olympic Games and the World Cup not only to acquire commercial interests therefrom, but also to effectively realize the target of city management. Thus, "success or failure of an Olympic Games held does not depend on temporary gain or loss, but on long term development of the host city. Without the Montreal Olympic Games in 1976, it would be difficult to image the development of this city as it is today" (Huang Wei, 2008). Centered by the three major ideals of "scientific Olympics, humanistic Olympics and green Olympics" in the 2008 Beijing Olympic Games, Beijing has built a traditional, modern and green city brand and has got wide commendation from all over the world.

In the traditional brand, Beijing Olympic Games was a great hand shaking of the Olympic Games with a history of 100 years with the Chinese civilization with a history of 5000 years, a magnificent converge of cultures from all over the world with the Chinese culture and is also an enthusiastic conversation between the eastern civilization and western civilization. In the modern brand, construction of Beijing Olympic stadium is a representation of harmonious combination of culture, history and the nature. In the green brand, construction of Beijing Olympic stadium embodies ecological greenness. The Olympic Village used recycled water heat pump system and the Olympic stadium adopted advanced sewage processing method and took the tough measures of Shougang move, channel cleanout, energy conservation and emission reduction, etc, to make Beijing reproduce green water and blue sky. The wood coverage rate of the whole city got close to $50 \%$; the wood coverage rate of the mountainous area attained up to $70 \%$; a green belt of trees with an area of 23,000 hectares was formed on both sides of "the five rivers and ten roads"; a green isolation belt with an area of 12,000 hectares was set up in the downtown; the three green protective screens were almost formed and the afforestation coverage rage of the city achieved above $40 \%$. In addition, the proportion of the days per year in Beijing with an air quality above the second level increased from previous $50 \%$ to the current $70 \%$ and Beijing promised its "green solutions". In the process of further pushing forward China from a major sports country to a sports power, we have to further lay emphasis on building the city brand, enhance the overall development level of the whole city and determine the central role of traditional, modern and green city brand in establishing a sports power.

\section{The status of enterprise brand in establishment of a sports power}

Quality is the life of an enterprise and brand is the eye of an enterprise. Today, the Olympic Games has already become a tremendous hatcher for the enterprise brand. It has become an important marketing strategy for the development of an enterprise to resort to the Olympic Games to enhance the international competitive force of the enterprise brand. "Statistically, in order for an enterprise to enhance its brand recognition degree within a worldwide scope, when they intend to enhance $1 \%$ of their recognition degree, they have to invest an advertising expense worthy of US\$0.1 billion, while if the same expense is used to sponsor a large-scale physical competition, such as, Olympic Games, then this recognition may be improved by as much as 3\%." (Lu Taihong \& Luo Qiming, 2003) Olympic economy has become an economic phenomenon which outshines others in the development of the world economy in the last three decades. The Olympic economy is a brand economy, and perfect operation might create a batch of well-known products and enterprise brands. Enterprises can explore deeply the connotation of "faster, higher and stronger" of the Olympic Games according to the different industries they are involved in and the features of their brands, and find out a rational explanation for their brands to express their strength and reputation. For example, Coca Cola, General Electric, Kodak, Madonald's, Matsushita and Samsung are typical examples. Ever since the Seoul Olympic Games in 1988, Samsung has become a global cooperative partner of the International Olympic Committee and has so far been the global cooperative partner of the International Olympic Committee for consecutively six times. Within the past two 
decades, Samsung has realized a leap from "Samsung of South Korea" to "Samsung of the world" and has become a global brand in digital electronics and home appliances. In the thirty years from the Reform and Opening up in China, a large number of large enterprises have appeared in China that are qualified to rank the top 500 enterprises in the world. Although the international recognition of these enterprises still have a long way to go compared with the international well-known brands of Coca Cola and Samsung, etc, enterprises in China have made full use of the Beijing Olympic Games opportunity to attempt to build their own brands. During the Beijing Olympic Games, the major brands built by domestic enterprises include proprietary and quality.

In the proprietary brand, during the Olympic Games, for the purpose of marketing mix in the design of the Olympic Games, brand marketing of Chinese enterprises highlighted proprietary and innovation. For instance, the Legend Holdings Ltd. resorted to the opportunity of the Beijing Olympic Games to fully present the technique of Legend and made its technical innovation to its perfection. Only the design and manufacturing of the "auspicious cloud torch" broke through more than ten proprietary and innovation techniques and created the imperishable history of the "auspicious cloud torch" on the Mount Everest. In the quality brand, Haier exploited its favorable conditions and avoided unfavorable conditions and successfully created the quality brands of energy conservation, environmental protection and service, etc. In addition to that, Haier also did a good job in the aspects of assuming the obligation of Olympic citizens and spreading the spirit and culture of the Olympic Games. In the process of further pushing forward China from a major sports country to a sports power, the enterprise brands of China should focus on improving their proprietary and quality value, and design a marketing mix based on such significant international competitions as the Olympic Games and the Asian Games, actively take part in construction and investment in professional sports, public sports and schools sports and confirm the economic status of the enterprise brands of proprietary and quality in establishing a sports power.

\section{The status of national citizen brand in establishment of a sports power}

The national brand is presentation of the national citizen quality. The national citizen quality refers to the capacity and quality of the entire nation in social activities. The national citizen quality means a lot to a country, and is related with the national fate and the future of the nation. In the last several years, Chinese countries have different opinions on Chinese people. A common evaluation on Chinese people is that although Chinese people created astonishing and splendid civilization, they completely don't possess the quality of modern industrial civilization. However, during the Olympic Games, Beijing Olympic Committee and relevant departments made concerted efforts and fully manifested the spiritual civilization and national citizen quality of the current Chinese nation and left a perfect impression on foreign guests by means of vigorously mobilizing, widely propagandizing and offering training and education. The national brands exhibited by the Beijing Olympic Games mainly include environmental protection, civilization, enthusiasm and smile.

In the environmental protection brand, Roger said, "Beijing Olympic Games enhanced the environmental protection consciousness of Beijing people and all Chinese people". For instance, the environmental protection education and propaganda activities held nationwide improved the environmental protection consciousness of the public. The environmental protection behaviors of garbage classification, planting carbon neutrality forests and stopping driving for one day, etc, got spread and became a new lightspot in the green Olympic Games. Today, the idea of environmental protection has been rooted in the heart of each national citizen. In the civilization brand, the ordinary people in Beijing practice with practical actions the slogan of "Welcome the Olympics, Improve Manners and Foster New Attitudes --- I Participate, I Contribute and I enjoy". In addition to this, the activity of "Improve Manners and Foster New Attitudes" in Beijing also has spread all over the Divine Land. Quite a large number of cities and towns, schools, organs and enterprises in the whole country print and distribute the civilization etiquette manual and propagandize this slogan. We treat with our guests from all over the world with politeness and also have gained respect of the whole world. Today, knowing about politeness, learning politeness and conducting politeness has become a fashion among Chinese citizens. In the enthusiasm brand, a team of volunteers composed by 100,000 Olympics volunteers, 400,000 urban volunteers, 1 million social volunteers and 200,000 cheering squad members as well as 550 urban service sites, offered excelsior service with a hundred times of attempts and a hundred times of enthusiasm under the infection of the slogan "I Participate, I Contribute and I enjoy". The civilization and friendliness of the Chinese nation with a history of five thousand years got thorough presentation during the Beijing Olympic Games. In the smile brand, 1.3 billion hosts held a grand global ceremony, which shocked the world not only for its grand momentum, but more for the happy ocean converged by a lot of contributions. In the enthusiasm of "Welcome the Olympics, Improve Manners and Foster New Attitudes", each Chinese citizen had a sunshine smile on their face and dedicated their enthusiastic and smiling services. On some competition fields, there was even the occasion in which both hosts and guests from both China and foreign countries cheered up for losers who were brave enough to struggle. 
These friendly behaviors embodied the universal love and lofty spirit. The Beijing Olympic spirit has pushed forward improvement of Chinese people, formation of their concepts and change of their living mode and has facilitated the overall development and modernization of Chinese people. In the process of further pushing forward China from a major sports country to a sports power, we ought to enable the civilization habits and good living modes that were advocated and followed during the Olympic Games to really take root in the Chinese society, "become part of the living mode of Chinese citizens (Ma Rong, 2008)", and endurably exhibit before people from all over the world. In such way, establishment of a sports power will not only have its traditional and modern features, which may ensure the basic status of the national brands of environmental protection, civilization, enthusiasm and smile in establishing a sports power.

\section{References}

Dong, Xiaoying \& Peng, Siqing. (2008). Olympic Games: Opportunity and Challenge to Enhancing the National Image. Science and Technology Review, 26(15):99.

Huang, Wei. (2008). Not to Determine Success or Failure with Profit or Loss.. China investment, 8:53.

Jin, Houzhong. (2010). Studies on Beijing Olympic Game's Spiritual Legacy: Brand Value. Sustainable Development, 6:255-260.

Lu, Taihong \& Luo, Qiming. (2003). Marketing Sports --- Olympics and World Cup. Sichuan: Sichuan People's Publishing House.

Ma, Rong. (2008). Switch of Thinking Mode --- The Most Important. Forum Rakyat, 234(9):19.

Qiu, Xue. (2010). The Establishment of Target System for Strong Sporting Nation. China Sport Science and Technology, 46(1):10-14.

Rio, Eric Alexander. (2006). Sports and City Marketing, translated by Shen, Tiyan,et al. Beijing: Oriental Press. 